\title{
Bibliometric Analysis of Global Research on Muskmelon (Cucumis melo L.) Based on Web of Science
}

\author{
Bao-Zhong Yuan \\ College of Plant Science and Technology, Huazhong Agricultural \\ University, Wuhan, Hubei, PR China, 430070
}

\author{
Zhi-Long Bie \\ College of Horticulture and Forestry, Huazhong Agricultural University, \\ Wuhan, Hubei, PR China, 430070
}

\section{Jie Sun \\ Library of Huazhong Agricultural University, Wuhan, Hubei, PR China, 430070}

Additional index words. bibliometric analysis, muskmelon, Cucumis melo, VOSviewer, Web of Science

\begin{abstract}
Muskmelon is a warm season cucurbit species that belongs to family Cucurbitaceae. We analyzed 2955 papers of global research on muskmelon (Cucumis melo L.) based on Web of Science from 1924 to 2021. Papers were mainly written in English (2766, 93.604\%), from 7883 authors, 83 countries or regions, 1697 organizations, and published in 585 journals and book series. The top five journals were HortScience (334, 11.303\%), Journal of the American Society for Horticultural Science (Proceedings of the American Society for Horticultural Science) (117, 3.959\%), Scientia Horticulturae (109, 3.689\%), Plant Disease (88, 2.978\%), and Phytopathology (84, 2.843\%), each of which published more than 84 papers. The top five countries or regions were the United States, PR China, Spain, Brazil, and Japan, which each published more than 168 papers. The top six organizations were U.S. Department of Agriculture Agricultural Research Service, Agricultural Research Organization, Texas A\&M University, Universitat Politecnica de Valencia, University of California-Davis and Consejo Superior de Investigaciones Cientificas, each of which published more than 64 papers. The top five authors are G.D. Lester, J.D. McCreight, J. Garcia-Mas, K.M. Crosby, and T.J. Ng, who each published more than 26 papers. On the basis of the analysis of a network map of VOSviewer, there were cooperation among authors, organizations, and countries or regions. All keywords of muskmelon research were separated into eight clusters for different research topics. Visualizations offer exploratory information on the current state and indicate possible developments in the future. This work is also useful for students identifying graduate schools and researchers selecting journals.
\end{abstract}

Muskmelon (Cucumis melo L.) is a cultivar of Cucumis melo and a warm-season cucurbit species that belongs to family cucurbitaceae (Farcuh et al., 2020; Jeffrey, 1980; Kirkbride, 1993). They are often readily available from the late summer to the early fall in the market. Muskmelon is enormously healthful because it is rich in ascorbic acid, carotene, folic acid, and potassium as well as several other bioactive

Received for publication 10 March 2021. Accepted for publication 3 May 2021.

Published online 18 June 2021.

This work was supported by China Agriculture Research System of MOF and MARA (CARS-25) and the Innovative Research Group Project of Natural Science Foundation of Hubei Province, China (2019CFA017).

B.-Z. Yuan and Z.-L. Bie are the corresponding authors. E-mail: yuanbz@mail.hzau.edu.cn or biezl@mail.hzau.edu.cn.

This is an open access article distributed under the CC BY-NC-ND license (https://creativecommons. org/licenses/by-nc-nd/4.0/). compounds (Thakur et al., 2019). Sweetness of the fruit, flavor or aroma, texture, and phytonutrients are the most important traits that determine consumer preference. Muskmelon varieties are mainly cultivated for their fruit, which differs in quality features such as organic acids, soluble sugars, vitamin, minerals, and sweet aromatic flavor (Kishor et al., 2021). Improvement in melon by traditional hybridization is relatively slow and is also restricted to a narrow gene pool. Biotechnological methods have been developed to increase the genetic diversity by somatic hybridization or gene transfer and to optimize conventional breeding programs through construction of a genetic map. To date, melon is an economically important fruit crop, and its production has become extremely common in China, especially under greenhouse cultivation (Zhang et al., 2020).

This study used elementary methods of bibliometrics and closely related informetrics or scientometrics, which are based on quantitative analysis and mapping of research in scholarly literature. Bibliometrics has been adopted in horticulture research on topics such as essential oil-bearing plants exposed to the water stress (Kulak et al., 2019); grafting in horticultural plants (Belmonte-Ureña et al., 2020); scientific research on fungus Phakopsora pachyrhizi Sydow and Sydow affecting soybean [Glycine max (L.) Merrill] (Meira et al., 2020); highly cited articles in the science citation index-expanded subject category of horticulture (Kolle et al., 2017); research, innovation, and development on Corylus avellana (Raparelli and Lolletti, 2020); berries (Yeung et al., 2019); analysis of INRA publications on fruits and vegetables produced between 2002 and 2006 (Tatry et al., 2011); analysis of INRA scientific academic literature on fruits and vegetables for the 2000-06 period (Leiser et al., 2009); tree fruit growing in Germany (Dalla Via and Baric, 2012); trends in Mango research (Kolle et al., 2018); wine research and its relationship to wine production (Jamali et al., 2020); and wine and grape research for wineproducing and consuming countries (Glanzel and Veugelers, 2006). This technique is also used in research related to irrigation and water use efficiency, such as soil and water conservation in the Loess Tableland-Gully Region of China (Wang et al., 2019), and advances in water use efficiency in agriculture and sustainable water use in agriculture (Velasco-Muñoz et al., 2018a, 2018b). Sun and Yuan have published some papers as rice with fertilizer based on CiteSpace (Sun and Yuan, 2019), the top papers in world rice research (Sun and Yuan, 2020a), Library and Information Science (Sun and Yuan, 2020b), water resources (Sun and Yuan, 2020c), green and sustainable science and technology (Yuan and Sun, 2019), agronomy (Sun and Yuan, 2021), and scientific research on maize or corn (Yuan and Sun, 2020a, 2020b).

The aim of the study was to assess global research publications on muskmelon ( $\mathrm{CuCu}$ mis melo L.) based on Web of Science (WoS) by bibliometric science mapping and visualization tools. We assessed the scatter of publications in citation databases, classification of topics, and progress over the years. Country input and author collaboration (coauthorship) are addressed. Special attention is dedicated to research topics and research fronts.

\section{Data and Methodology}

Web of Science. Clarivate Analytics' WoS is the world's leading scientific citation search and analytical information platform and the one of the world's largest and most comprehensive academic information resources covering more than 12,361 core academic journals. The publication counts from the WoS Core Collection were derived from the following databases: The Science Citation Index-Expanded (SCIE)1900-present, Social Science Citation Index (SSCI) - 1900-present, Conference Proceeding Citation Index-Science (CPCI-S)-2015-present, Conference Proceedings Citation IndexSocial Science \& Humanities (CPCI-SSH) 2015-present, Current Chemical Reactions 
(CCR-EXPANDED)-1985-present, Index Chemicus (IC) - 1993-present.

Data collection and analysis. This study surveyed papers in WoS Core Collection (retrieval data last updated: 15 Feb. 2021). We used the keywords in the topic, with the query Topic = ("Muskmelon" OR "Cucumis melo L.")

There are 2955 papers from the WoS Core Collection. Full record and cited references of the included papers were extracted at other reference software file formats and imported into VOSviewer (version 1.6.16, 2020, Leiden University, Leiden, The Netherlands) for further citation analysis. The impact factors (IF 2019 and IF 5 year) were taken from the Journal Citation Report (JCR 2019) published in 2020, which had the latest data available.

VOSviewer. Visualizations (network and overlay) using program VOSviewer are conducted on WoS data to determine co-occurrence and clusters of connected publications, country input and author collaboration (coauthorship) as well as clusters of interrelated research topics (text data). In this work, we used VOSviewer to indicate the international collaboration between the authors, organizations, countries, and the research trends through all keywords (Van Eck and Waltman, 2010). In this article, default parameters values of the VOSviewer were usually used in the analysis. Items are represented by a label and a circle. The size of circles reflects the weight of an item. Some items are not displayed to avoid overlap. The colors in network visualization (text maps) represent clusters of similar items as calculated by the program. Distance between the items indicates the strength of relationships.

\section{Results and Discussion}

Document type and language of publication. On the basis of Clarivate Analytics' WoS Index, the 2955 papers were SCIE (2902), CPCI-S (109), SSCI (11), IC (4), Arts and Humanities Citation Index (4), and Book Citation Index-Science (1). The first paper titled of "A Seedless Muskmelon," written by L.J. Cole (1924), was published in 1924 in Journal of Heredity (15:219-219).

The published document types and languages are described in Table 1. Among the document types, there were articles (2536, $85.821 \%)$, meeting abstracts (188, 6.362\%), notes $(94,3.181 \%)$, proceedings papers $(84$, $2.843 \%)$, reviews $(53,1.794 \%)$, and editorial material $(14,0.474 \%)$, for example. Most of the articles were published in English (2766, 93.604\%), and then in Portuguese (92, $3.113 \%)$, Japanese $(29,0.981 \%)$, French (23, $0.778 \%)$, Spanish $(19,0.643 \%)$, Chinese (11, $0.372 \%)$, Korean $(10,0.338 \%)$, and German (2, $0.068 \%)$. English was dominant language from the WoS; scholars tended to publish their articles in English because they want them to be widely accepted. Moreover, most published documents were in the form of original research articles written in English (Khan et al., 2020).

Table 1. Document type and language of publication of muskmelon research.

\begin{tabular}{|c|c|c|c|c|c|c|}
\hline \multirow[b]{2}{*}{ Rank } & \multicolumn{3}{|c|}{ Document type } & \multicolumn{3}{|c|}{ Language } \\
\hline & Document type & Records & $\%$ Total papers & Language & Records & $\%$ Total papers \\
\hline$\overline{1}$ & Article & 2,536 & 85.821 & English & 2,766 & 93.604 \\
\hline 2 & Meeting abstract & 188 & 6.362 & Portuguese & 92 & 3.113 \\
\hline 3 & Note & 94 & 3.181 & Japanese & 29 & 0.981 \\
\hline 4 & Proceedings paper & 84 & 2.843 & French & 23 & 0.778 \\
\hline 5 & Review & 53 & 1.794 & Spanish & 19 & 0.643 \\
\hline 6 & Editorial material & 14 & 0.474 & Chinese & 11 & 0.372 \\
\hline 7 & Early access & 6 & 0.203 & Korean & 10 & 0.338 \\
\hline 8 & News item & 6 & 0.203 & German & 2 & 0.068 \\
\hline 9 & Correction & 5 & 0.169 & Italian & 1 & 0.034 \\
\hline 10 & Letter & 5 & 0.169 & Polish & 1 & 0.034 \\
\hline 11 & Correction addition & 2 & 0.068 & Turkish & 1 & 0.034 \\
\hline 12 & Book chapter & 1 & 0.034 & & & \\
\hline 13 & Data paper & 1 & 0.034 & & & \\
\hline
\end{tabular}

Publication output. With the aim of knowing the trend in muskmelon research, a total of 2955 publications were obtained from the online version of WoS database from 1924 to 2021 (Fig. 1). The most papers (145) were published in 2019. In general, the quantity of muskmelon research literature began increasing after 1971. There are 41, 132, 257, 566, 715 and 1078 papers published during the periods of 1960-69, 1970-79, 1980-89, 1990-99, 2000-09, and 2010-19, respectively.

WoS categories and research areas. For muskmelon research from 1924 to the present, there are $93 \mathrm{WoS}$ subject categories in the science edition (254 categories) and 60 research areas. Table 2 shows the top $20 \mathrm{WoS}$ categories and top 20 research areas on the subject of muskmelon research. The top five WoS categories include Plant Sciences (1046, 35.398\%), Horticulture (958, 32.42\%), Agronomy (494, $16.717 \%$ ), Food Science Technology (281, 9.509\%), and Agriculture Multidisciplinary $(216,7.31 \%)$. The top five research areas include Agriculture (1519, 51.404\%), Plant Sciences (1046, 35.398\%), Food Science Technology (281, 9.509\%), Biotechnology Applied Microbiology $(154,5.212 \%)$, and Chemistry (152, $5.144 \%$ ). The journals or papers either classified in two or more categories in the WoS shows the

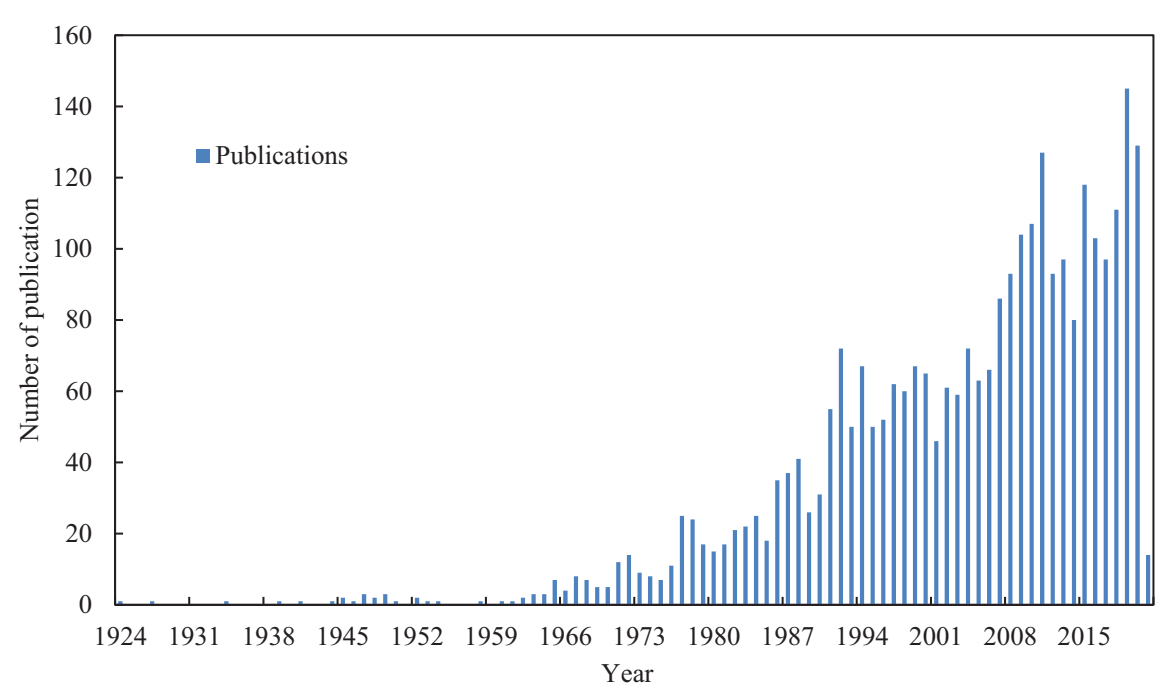

Fig. 1. Number of published papers of muskmelon research from 1924 to 2021. multidisciplinary character of this research field (Elango and Ho, 2017, 2018). Documents are mapped to one or several research areas in WoS. Areas are assigned to publications and then mapped to each document (paper) in a publication. Therefore, publications can be mapped to several areas. In WoS, publications are also mapped to WoS categories which are more detailed than areas (Stopar et al., 2019).

Core journals. Based on JCR 2019 data (published in 2020), there were 585 journals and book series of the WoS categories for muskmelon research from 1924 to 2021. Among these, the 11 book series includes Acta Horticulturae, AIP Conference Proceedings, ACS Symposium Series, AER Advances in Engineering Research, IOP Conference Series Earth and Environmental Science, for example. The top 22 journals with IF (IF 2019 and IF 5 years), rank, and quartile in category are displayed in Table 3. Each journal contains more than 23 published papers. In general, we combined the current and formerly journal title (Table 3), but the total number of journals in the WoS were calculated separately.

The top 5, top 10 , top 15 , and top 20 journals published approximately $24.467 \%$, $30.897 \%, 36.277 \%$, and $40.406 \%$ of the total papers, respectively. The top five journals are 
Table 2. Relevance of the 2955 total melon papers published from 1924 through 2021 to the top 20 Web of Science (WoS) categories and research areas; some papers were relevant to more than one category or area.

\begin{tabular}{|c|c|c|c|c|c|c|}
\hline \multirow[b]{2}{*}{ Rank } & \multicolumn{3}{|c|}{ WoS categories } & \multicolumn{3}{|c|}{ Research areas } \\
\hline & Categories & $\begin{array}{c}\text { No. } \\
\text { papers }\end{array}$ & $\begin{array}{l}\% \text { Total } \\
\text { papers }\end{array}$ & Areas & $\begin{array}{c}\text { No. } \\
\text { papers }\end{array}$ & $\begin{array}{l}\% \text { Total } \\
\text { papers }\end{array}$ \\
\hline 1 & Plant sciences & 1,046 & 35.398 & Agriculture & 1,519 & 51.404 \\
\hline 2 & Horticulture & 958 & 32.42 & Plant sciences & 1,046 & 35.398 \\
\hline 3 & Agronomy & 494 & 16.717 & Food science technology & 281 & 9.509 \\
\hline 4 & Food science technology & 281 & 9.509 & $\begin{array}{l}\text { Biotechnology applied } \\
\text { microbiology }\end{array}$ & 154 & 5.212 \\
\hline 5 & Agriculture multidisciplinary & 216 & 7.31 & Chemistry & 152 & 5.144 \\
\hline 6 & $\begin{array}{l}\text { Biotechnology applied } \\
\text { microbiology }\end{array}$ & 154 & 5.212 & $\begin{array}{l}\text { Biochemistry molecular } \\
\text { biology }\end{array}$ & 128 & 4.332 \\
\hline 7 & Genetics heredity & 120 & 4.061 & Genetics heredity & 120 & 4.061 \\
\hline 8 & $\begin{array}{l}\text { Biochemistry molecular } \\
\text { biology }\end{array}$ & 119 & 4.027 & Entomology & 107 & 3.621 \\
\hline 9 & Entomology & 107 & 3.621 & $\begin{array}{l}\text { Science technology other } \\
\text { topics }\end{array}$ & 75 & 2.538 \\
\hline 10 & Chemistry applied & 103 & 3.486 & $\begin{array}{l}\text { Environmental sciences } \\
\text { ecology }\end{array}$ & 61 & 2.064 \\
\hline 11 & Multidisciplinary sciences & 69 & 2.335 & $\begin{array}{l}\text { Life sciences biomedicine } \\
\text { other topics }\end{array}$ & 41 & 1.387 \\
\hline 12 & Soil science & 60 & 2.03 & Nutrition dietetics & 38 & 1.286 \\
\hline 13 & Environmental sciences & 48 & 1.624 & Engineering & 34 & 1.151 \\
\hline 14 & Biology & 41 & 1.387 & Cell biology & 28 & 0.948 \\
\hline 15 & Nutrition dietetics & 38 & 1.286 & Water resources & 28 & 0.948 \\
\hline 16 & Agricultural engineering & 36 & 1.218 & Microbiology & 25 & 0.846 \\
\hline 17 & Chemistry analytical & 33 & 1.117 & Evolutionary biology & 17 & 0.575 \\
\hline 18 & Cell biology & 28 & 0.948 & Pharmacology pharmacy & 17 & 0.575 \\
\hline 19 & Water resources & 28 & 0.948 & Virology & 15 & 0.508 \\
\hline 20 & Microbiology & 25 & 0.846 & Mycology & 12 & 0.406 \\
\hline
\end{tabular}

HortScience (334, 11.303\%), Journal of the American Society for Horticultural Science (Proceedings of the American Society for Horticultural Science; 117, 3.959\%), Scientia Horticulturae (109, 3.689\%), Plant Disease (88, $2.978 \%$ ), and Phytopathology (84, 2.843\%), each of which published more than 84 papers. On the basis of the results shown in Table 3, among the top 22 journals, 11 were in quartile highest visibility and scientific impact, followed by interinstitutional collaborative articles, single-country articles, and single-author articles, respectively (Wambu and Ho, 2016). According to the published data analysis results, 7883 authors had 2955 publications, and among these, 253 authors met the threshold of five publications, but only 73 authors were connected with each other. The network of authorship in the field of muskmelon research is represented in Fig. 2; the size of the circles reflects the total number of records. Authors in the same cluster usually suggested that they studied in a similar field or worked at the same institute or had close cooperation with each other.

Details on author information of published articles on muskmelon from 1924 to 2021 , along with citation, average citations, organization, and countries are provided in Table 4. According to our analysis, the top 21 authors published more than 19 papers. We combined the same author with different spellings, but the total number of authors were calculated separately. The top five authors were Gene E. Lester, James D. McCreight, Jordi Garcia-Mas, Kevin M. Crosby, and T.J. Ng., each of whom published more than 26 papers. The top 21 authors were mainly from the United States, Israel, and Spain. There were 10 authors from the United States; organizations included the U.S. Department of Agriculture Agricultural Research Service (USDA ARS), Texas A\&M University System, University of Wisconsin System, University of California Berkeley, Virginia Polytechnic Institute \& State University and University of California-Davis; four authors from Israel were from the Agricultural Research Organization (ARO), and Bar Ilan University; four authors from Spain were from the University of Barcelona and Universitat Politecnica de Valencia; one author was from the INRAE Genet \& Ameliorat Fruits \& Legumes of France; one author was from Universidade Federal Rural do Semi-Arido of Brazil; one author was from the Singapore Institute of Manufacturing Technology. The five authors with the highest average citations per paper were N. Katzir, Antonio J. Monforte, Jordi Garcia-Mas, M. Pitrat, and Jack E. Staub.

Countries/regions coauthorship analysis. There were 83 countries or regions that contributed 2955 papers in muskmelon research. Table 5 lists the top 20 countries or regions that published more than 25 papers and also shows the cluster, total link strength, citations, and average citations. Among 20 countries, the United States, PR China, Spain, Brazil, and Japan were the major article contributors. For average number of citations, England, Germany, France, Israel, and Greece had the higher citations per paper.

We developed the coauthorship network map using VOSviewer (Fig. 3). Forty-three countries or regions met the requirement threshold of five. The size of circles in Fig. 3 reflects the total number of records, and the distance between countries indicates the strength of relationships. The VOSviewer divided these circles into nine clusters. The different colors represent the different clusters formed by sets of countries. Distance 
beaulieu, jc

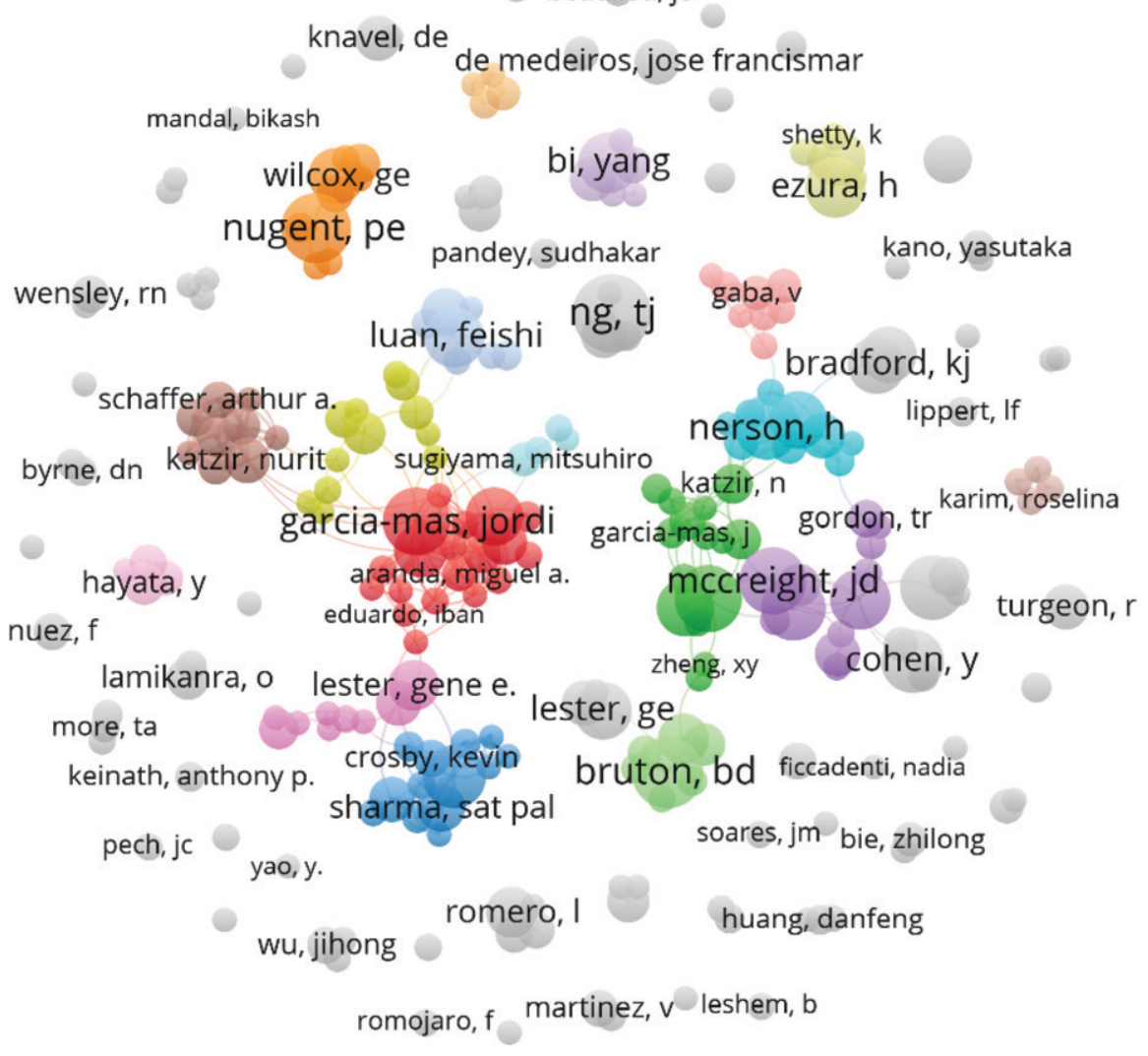

Fig. 2. Network visualization maps of authors in muskmelon research from 1924 to 2021.

between the countries indicates the strength of the relationships.

As shown in Fig. 3, the first cluster consisted of nine countries or regions (red) including the United States, Japan, South third cluster consisted of six countries (dark blue) including PR China, India, Canada, Pakistan, Egypt, and Saudi Arabia. The fourth cluster consisted of five countries and regions (yellow color) including Italy, England, Greece, Cyprus, and Denmark. The fifth cluster consisted of four countries (violet) including Brazil, France, Argentina, and Venezuela. The sixth cluster consisted of four countries (light) including Turkey, Iran, Hungary, and Switzerland. The seventh cluster consisted of three countries (orange) including Australia, the Netherlands, and Oman. The eighth cluster consisted of three countries (brown) including Germany, Czech Republic, and Sudan. The ninth cluster consisted of two countries (pink) including Israel and Austria. More cooperation could bring more advances in scientific research. Today, increasing international exchange has promoted academic communications (Tang et al., 2018).

Organization coauthorship analysis. According to the publication data, it was revealed that 1697 organizations had 2955 publications. Organization coauthorship analysis reflects the degree of communication between institutions as well as the influential institutions in this field (Reyes-Gonzalez et al., 2016). Table 6 represents the top 22 organizations and institutions ranked by the number of total publications (more than 25 papers), the total link strength, citations, average citations, and country. We combined the same organization with different spelling, but the total organization numbers in the WoS were calculated separately. These 22 organizations were mainly based in the United States (12 organizations), China (three organizations), Spain (two organizations), Brazil (two organizations), Israel (two organization),

Table 4. The top 21 most prolific authors published papers in the field of muskmelon research from 1924 to 2021.

\begin{tabular}{|c|c|c|c|c|c|c|}
\hline$\underline{\text { Rank }}$ & Author & Papers & Citations & Avg citations & Organization & Country \\
\hline$\overline{1}$ & $\begin{array}{l}\text { Lester, Gene E. (Lester, Gene; Lester, } \\
\text { GE; Lester, G) }\end{array}$ & 49 & 1,217 & 24.84 & USDA ARS & USA \\
\hline 2 & $\begin{array}{l}\text { McCreight, James D. (McCreight, J.D.; } \\
\text { McCreight, JD) }\end{array}$ & 40 & 765 & 19.13 & USDA ARS & USA \\
\hline 3 & Garcia-Mas, Jordi (Garcia-Mas, J) & 28 & 1,195 & 42.68 & University of Barcelona & Spain \\
\hline 4 & Crosby, Kevin M. (Crosby, Kevin) & 28 & 257 & 9.18 & Texas A\&M University & USA \\
\hline 5 & $\mathrm{Ng}, \mathrm{TJ}$ & 26 & 143 & 5.50 & $\begin{array}{l}\text { Singapore Institute of } \\
\text { Manufacturing Technology }\end{array}$ & Singapore \\
\hline 8 & Bruton, BD & 23 & 376 & 16.35 & USDA ARS & USA \\
\hline 9 & $\begin{array}{l}\text { De Medeiros, Jose Francismar } \\
\text { (De Medeiros, Jose F) }\end{array}$ & 23 & 114 & 4.96 & $\begin{array}{l}\text { Universidade Federal Rural } \\
\text { do Semi-Arido }\end{array}$ & Brazil \\
\hline 10 & Katzir, Nurit (Katzir, N) & 22 & 1,389 & 63.14 & ARO & Israel \\
\hline 11 & Edelstein, Menahem (Edelstein, M) & 22 & 509 & 23.14 & ARO & Israel \\
\hline 12 & Nugent, PE & 22 & 165 & 7.50 & UC Berkeley & USA \\
\hline 13 & Monforte, Antonio J. (Monforte, AJ) & 21 & 1,000 & 47.62 & UPV & Spain \\
\hline 16 & Nuez, Fernando (Nuez, F) & 21 & 442 & 21.05 & UPV & Spain \\
\hline 17 & Bohn, GW & 20 & 425 & 21.25 & USDA ARS & USA \\
\hline 18 & Nerson, $\mathrm{H}$ & 20 & 166 & 8.30 & ARO & Israel \\
\hline 19 & Zink, FW & 20 & 166 & 8.30 & UC Davis & USA \\
\hline 20 & Cohen, Y & 19 & 475 & 25.00 & Bar Ilan University & Israel \\
\hline 21 & Jifon, John L. (Jifon, John) & 19 & 89 & 4.68 & Texas A\&M University & USA \\
\hline
\end{tabular}

ARO = Agricultural Research Organization; UC = University of California; UPV = Universitat Politecnica de Valencia; USDA ARS = U.S. Department of Agriculture Agricultural Research Service. 
Table 5. Top 20 countries or regions publishing papers in the field of muskmelon research from 1924 to 2021 .

\begin{tabular}{|c|c|c|c|c|c|c|}
\hline Rank & Countries/Regions & Records & Cluster & $\begin{array}{l}\text { Total link } \\
\text { strength }\end{array}$ & Citations & $\begin{array}{c}\text { Avg } \\
\text { citations }\end{array}$ \\
\hline$\overline{1}$ & USA & 808 & 1 & 213 & 17,901 & 22.15 \\
\hline 2 & PR China & 322 & 3 & 78 & 3,751 & 11.65 \\
\hline 3 & Spain & 274 & 2 & 122 & 6,898 & 25.18 \\
\hline 4 & Brazil & 200 & 5 & 27 & 1,297 & 6.49 \\
\hline 5 & Japan & 168 & 1 & 43 & 2,917 & 17.36 \\
\hline 6 & Israel & 153 & 9 & 82 & 5,076 & 33.18 \\
\hline 7 & India & 124 & 3 & 24 & 1,132 & 9.13 \\
\hline 8 & Turkey & 102 & 6 & 31 & 1,515 & 14.85 \\
\hline 9 & France & 95 & 5 & 70 & 3,237 & 34.07 \\
\hline 10 & Italy & 90 & 4 & 43 & 2,040 & 22.67 \\
\hline 11 & South Korea & 75 & 1 & 23 & 1,401 & 18.68 \\
\hline 12 & Canada & 45 & 3 & 24 & 978 & 21.73 \\
\hline 13 & Iran & 45 & 6 & 16 & 338 & 7.51 \\
\hline 14 & Mexico & 42 & 2 & 19 & 350 & 8.33 \\
\hline 15 & Australia & 27 & 7 & 13 & 722 & 26.74 \\
\hline 16 & England & 26 & 4 & 22 & 1,019 & 39.19 \\
\hline 17 & Malaysia & 26 & 1 & 9 & 312 & 12.00 \\
\hline 18 & Pakistan & 26 & 3 & 18 & 398 & 15.31 \\
\hline 19 & Germany & 25 & 8 & 23 & 918 & 36.72 \\
\hline 20 & Greece & 25 & 4 & 13 & 705 & 28.20 \\
\hline
\end{tabular}

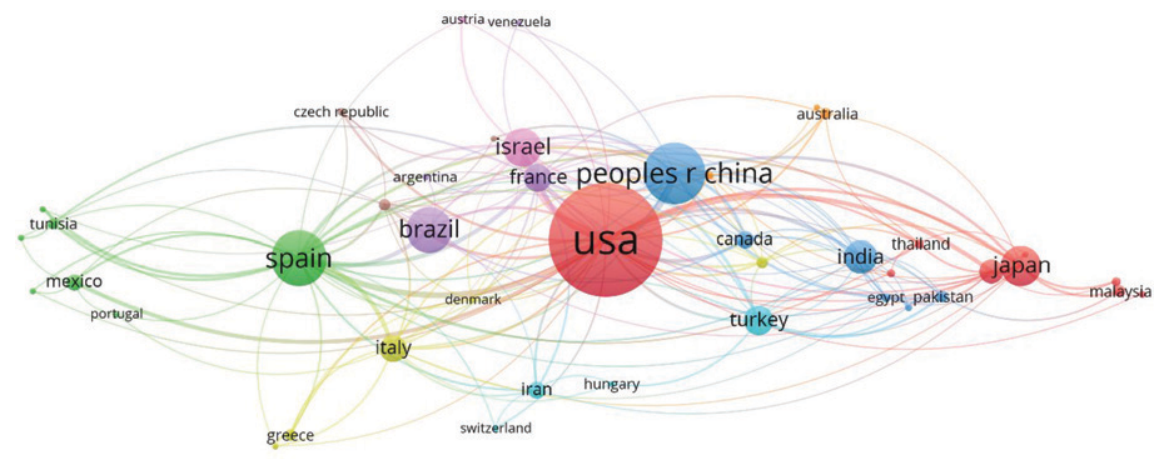

Fig. 3. The country coauthorship network of muskmelon research from 1924 to 2021 with 43 circles and nine clusters.

Table 6. Top 22 organizations publishing papers in the field of muskmelon research from 1924 to 2021.

\begin{tabular}{|c|c|c|c|c|c|c|}
\hline Rank & Organizations & Records & $\begin{array}{l}\text { Total link } \\
\text { strength }\end{array}$ & Citations & $\begin{array}{l}\text { Avg } \\
\text { citations }\end{array}$ & Country \\
\hline 1 & $\begin{array}{l}\text { U.S. Department of Agriculture } \\
\text { Agricultural Research Service }\end{array}$ & 187 & 135 & 5,748 & 33.74 & $\overline{\text { USA }}$ \\
\hline 2 & Agricultural Research Organization & 94 & 81 & 3,277 & 34.86 & Israel \\
\hline 3 & Texas A\&M University & 78 & 29 & 871 & 11.17 & USA \\
\hline 4 & Universitat Politecnica de Valencia & 74 & 65 & 1,852 & 25.03 & Spain \\
\hline 5 & University of California Davis & 64 & 27 & 1,487 & 23.23 & USA \\
\hline 6 & $\begin{array}{l}\text { Consejo Superior de Investigaciones } \\
\text { Cientificas }\end{array}$ & 64 & 42 & 2,139 & 33.42 & Spain \\
\hline 7 & University Florida & 55 & 22 & 740 & 13.45 & USA \\
\hline 8 & $\begin{array}{l}\text { Universidade Federal Rural do } \\
\text { Semi-Arido }\end{array}$ & 47 & 34 & 200 & 4.26 & Brazi \\
\hline 9 & $\begin{array}{l}\text { Institut National de la Recherche } \\
\text { Agronomique }\end{array}$ & 47 & 16 & 1,745 & 37.13 & France \\
\hline 10 & Cornell University & 46 & 33 & 2,143 & 46.59 & USA \\
\hline 11 & Purdue University & 44 & 14 & 356 & 8.09 & USA \\
\hline 12 & Hebrew University Jerusalem & 35 & 34 & 1,507 & 43.06 & Israel \\
\hline 13 & University Maryland & 33 & 24 & 320 & 9.70 & USA \\
\hline 14 & Ministry of Agriculture & 32 & 31 & 334 & 10.44 & China \\
\hline 15 & University Wisconsin & 31 & 35 & 1,411 & 45.52 & USA \\
\hline 16 & Gansu Agriculture University & 30 & 15 & 545 & 18.17 & China \\
\hline 17 & Clemson University & 28 & 22 & 506 & 18.07 & USA \\
\hline 18 & Iowa State University & 28 & 11 & 200 & 7.14 & USA \\
\hline 19 & Michigan State University & 27 & 12 & 553 & 20.48 & USA \\
\hline 20 & Universidade Federal do Ceara & 27 & 23 & 223 & 8.26 & Brazil \\
\hline 21 & Northeast Agriculture University & 25 & 22 & 86 & 3.44 & China \\
\hline 22 & University of California, Riverside & 25 & 21 & 642 & 25.68 & USA \\
\hline
\end{tabular}

and France (one organization). Furthermore, the organizations of USDA ARS, Agricultural Research Organization (ARO), Texas A\&M University, Universitat Politecnica de Valencia, University of California-Davis and Consejo Superior de Investigaciones Cientificas were popular based on the contribution of articles more than 64 papers each. Similarly, with regard to citations, Cornell University, the University of Wisconsin, Hebrew University Jerusalem, Institut National de la Recherche Agronomique, and ARO showed the highest average citations with more than 34.86 citations per paper.

Among the total 1697 organizations, 181 met the minimum threshold of five, but 169 organizations were connected to each other (Fig. 4). The VOSviewer software divided these 169 institutes into 18 clusters with different colors. Within the context of network formation, organizations tend to form bonds with other institutions in the same region. Geographic localization is an important factor for partnership and joint ventures. Therefore, there is a heavy presence of intrainstitutional relationships within the scientific network on publications.

All keywords cooccurrence analysis. Figure 5 shows the network map that links all keywords to the entire sample of the articles analyzed. Among all 8655 keywords, only 889 met the threshold level of more than five times included in the map. There are eight main clusters that represent different viewpoints on muskmelon research (Fig. 5). The top 20 cooccurrence keywords were muskmelon, Cucumis melo, melon, growth, $\mathrm{Cucu}$ mis melo L., yield, quality, plants, resistance, identification, fruit, cantaloupe, tomato, $\mathrm{Cucu}$ mis-melo, Cucumis-melo L., expression, watermelon, storage, disease, and ethylene.

The same data were then arranged by a period of muskmelon research as overlay map (Fig. 6). Blue colors indicate earlier research topics, whereas yellow and green colors indicate more recent topics of interest. The bluecolored topics do not indicate that there is no longer research work on that topics. Rather, it usually indicates that, on average, this topic was intensely investigated earlier and attention has shifted toward other topics. For example, the circle for ethylene, acid invertase, сисиmis-melo L. and somatic embryogenesis are represented in dark blue. Perhaps these terms are now so general that they are no longer extensively used as keywords. Yellow and green circles present those research fronts. For example, growth and fruit quality at left in Fig. 5 can be observed in Fig. 6 with yellow circles or shallow-green in the same position.

Visualization conducted on large datasets (big data) offer exploratory information on the current state in a scientific field or discipline and indicate possible future developments. Here, the top 20 keywords are list and ranked in each cluster.

The first cluster (red) is focused on biological-control disease management of muskmelon and includes keywords such as muskmelon, watermelon, disease, cucumber, soil, cucurbits, management, nitrogen, wilt, 


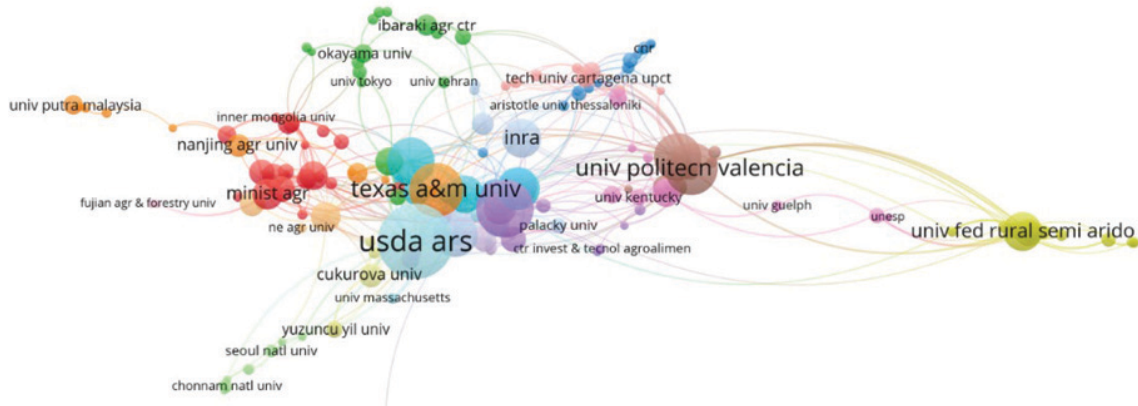

biological control, f-sp melonis, fungi, root rot, vine decline, fusarium wilt, citrullus lanatus, colonization, cotton, and pathogenicity.

The second cluster (green) represents the genetic diversity and disease resistance of the Cucumis melo and includes keywords such as Cucumis melo, melon, resistance, identification, Cucumis-melo L., cultivars, cucurbitaceae, inheritance, diversity, genetic diversity, disease resistance, markers, powdery mildew, RAPD, germplasm, genes, DNA, linkage map, sequence, and evolution.

The third cluster (blue) is focused on fruit quality, and include keywords such as quality, fruit, cantaloupe, storage, Cucumis melo L., acid, vegetables, fruits, shelf life, honeydew, beta-carotene, flavor, firmness, maturity, aroma, color, antioxidant activity, postharvest, carotenoids, and system.
The fourth cluster (yellow) represents ethylene metabolism gene expression in $\mathrm{Cucu}$ mis melo L., and keywords include as tomato, Cucumis-melo L., expression, ethylene, metabolism, gene, leaves, plant, arabidopsis, arabidopsis-thaliana, biosynthesis, tomato fruit, protein, purification, transport, proteins, sugar, melon (Cucumis melo L.), fruit ripening, and abscisic acid.

The fifth cluster (violet) is focused on stresses affecting plants growth and yield and includes keywords such as growth, Cucumis melo L., yield, plants, stress, accumulation, salinity, fruit-quality, salt tolerance, responses, tolerance, Cucumis-melo L., fruit quality, irrigation, photosynthesis, water, oxidative stress, grafting, salt stress, and model.

The sixth cluster (shallow blue) is focused on plant regeneration and somatic

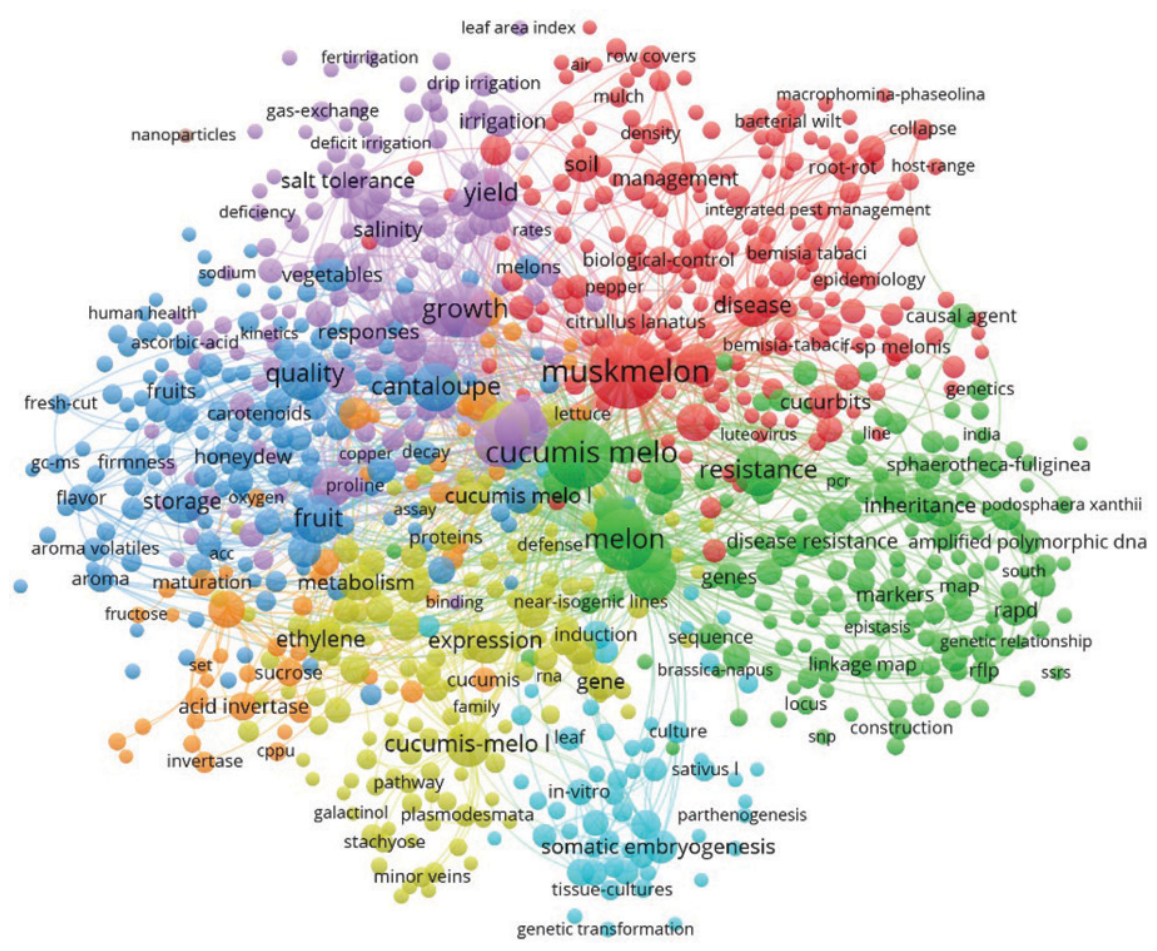

Fig. 5. VOSviewer co-occurrence network visualization mapping of most frequent all keywords (minimum of five occurrences) in muskmelon research from 1924 to 2021. embryogenesis. Keywords are ranked as somatic embryogenesis, plant regeneration, induction, regeneration, pollination, in vitro, transformation, explants, organogenesis, cotyledons, agrobacterium-mediated transformation, leaf, shoot regeneration, culture, cells, Sativus L., pumpkin, cotyledon, genotype, and tissue cultures, for example.

The seventh cluster (orange) is focused on temperature affecting muskmelon fruit seed germination, and keywords include temperature, muskmelon fruit, germination, water relations, acid invertase, enzymes, sucrose, maturation, Cucumis, sugar accumulation, fruit development, seed, sucrose-phosphate synthase, invertase, seeds, seed development, lettuce, abscisic acid, CPPU, and survival, for example.

The eighth cluster (crown) has only one keyword, nanoparticles, in the upper left corner.

Top papers based on Essential Science Indicators. Top papers are the sum of hot papers and highly cited papers, based on Clarivate Analytics' Essential Science Indicators (ESI). A highly cited paper is a one that belongs to the top $1 \%$ of papers in a research field published in a specified year. The $1 \%$ is determined by the highly cited threshold calculated for the research field in the specified year. A hot paper is a one published in the past 2 years that received a number of citations in the most recent 2-month period that places it in the top $0.1 \%$ of papers in the same field. Here, the ESI database has been updated as of 21 Jan. 2021, and data cover a 10-year and 10-month period: 1 Jan. 2010 to 31 Oct. 2020.

On the basis of ESI database, there are three highly cited papers and no hot papers. The three top papers were published in Phytochemistry, BMC Plant Biology, and Plant Physiology and Biochemistry in 2017, 2019, and 2020, respectively (Table 7).

The most frequently cited articles. Citation analysis has been employed as a supplementary index to determine the impact of scientific studies and to identify studies, researchers, and the most renowned institutions dealing with the theme. Although a great many articles have been published, a relatively small number of individuals account for a large proportion of the citations within the period. The annual citations of the eight papers showed an increasing trend after year of publication (Fig. 7). Here, the total citations for the most frequently cited articles was greater than 284 times. The time dependence of a single paper is called its history. In the first year (year zero here), generally the articles have fewer citations because it is the year of publication. In Fig. 7, it can be seen that the citation per year of the papers increased up to 2020, but the increase rate was different each year. Among eight articles, the highest average citation per year (43.11, blue) was observed for an article by Kloepper et al. (2004) published in Phytopathology (Fig. 7); the other seven papers were written by McDonald (1999), Lelievre et al. (1997), Garcia-Mas et al. (2012), Choudhary and Johri (2009), Hubbard et al. (1989), Turgeon and Wolf (2009), and Miron and Schaffer (1991). 


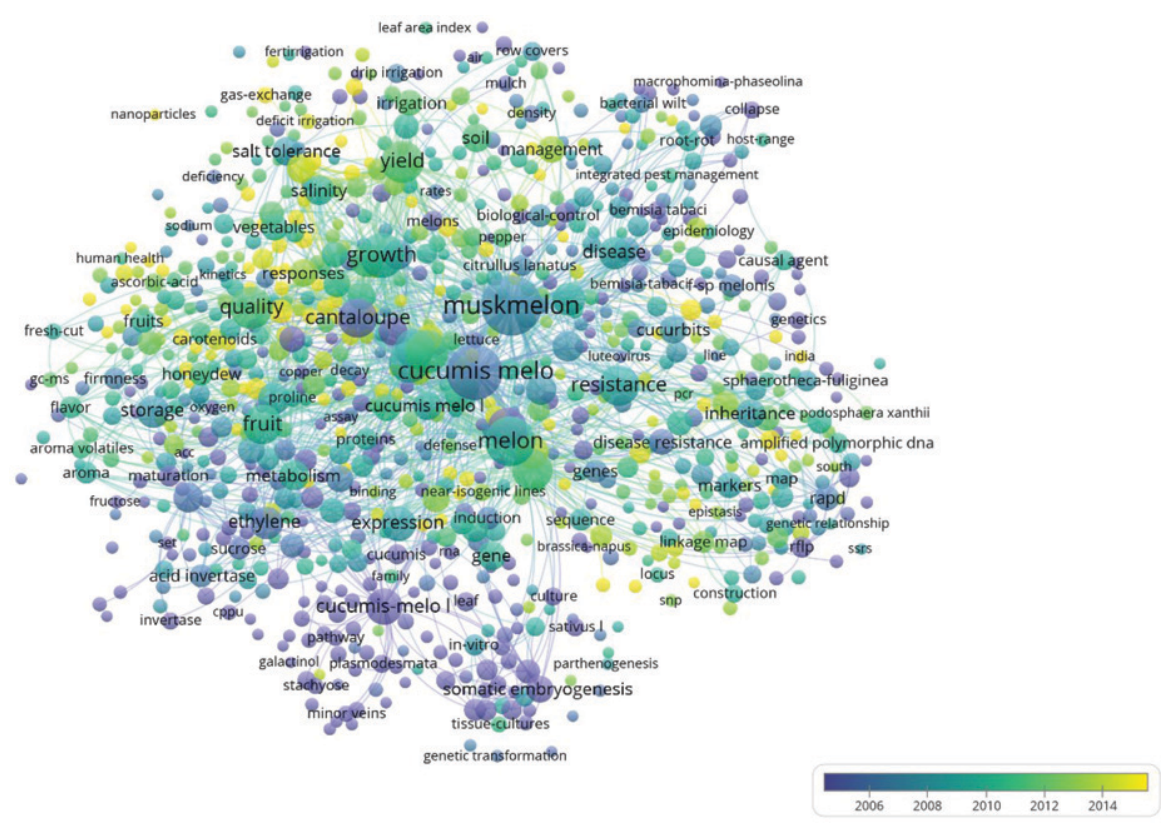

Fig. 6. VOSviewer co-occurrence overlay visualization mapping of most frequent all keywords (minimum of five occurrences) in muskmelon research from 1924 to 2021.

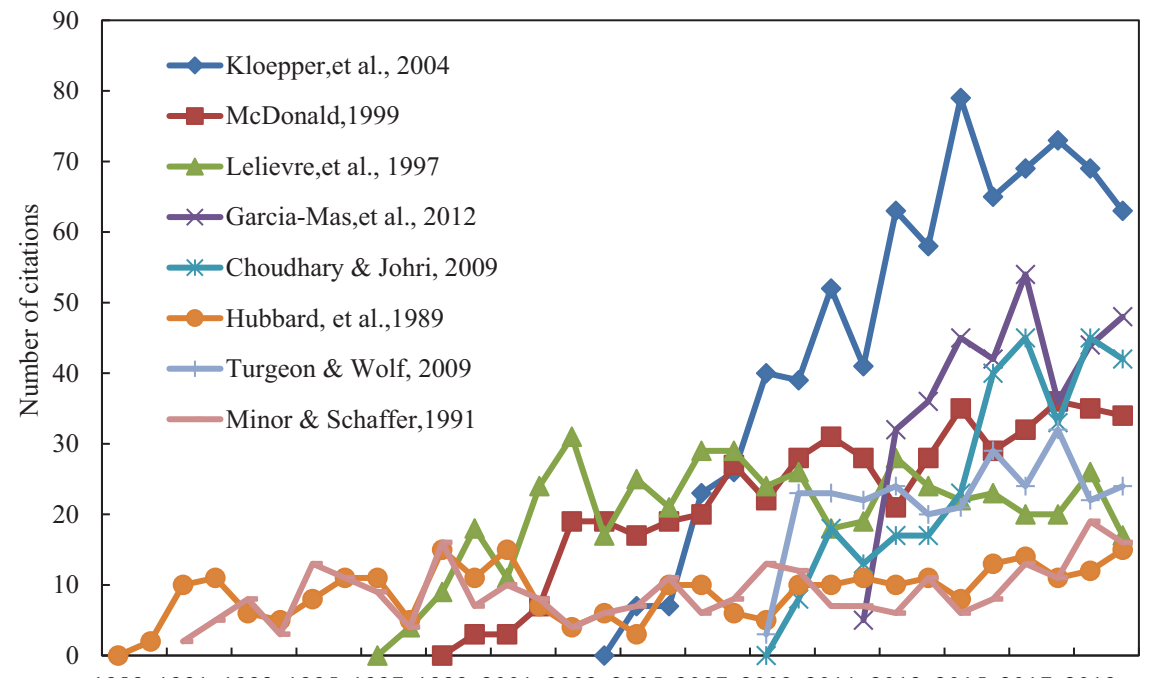

1989199119931995199719992001200320052007200920112013201520172019

Year

Fig. 7. Comparison of the citations per year of the top eight papers from their initial publications to 15 Feb. 2021

An increase in the number of cited references indicates that there are more citing or cited publications. The number of citations to a paper is considered a good quantitative measure of a paper's impact. The $h$-index was initially proposed as a measure of a researcher's scientific output based on counting the number

Table 7. Top papers of three highly cited papers based on Essential Science Indicators.

\begin{tabular}{llll}
\hline Rank & \multicolumn{1}{c}{ References } & TC & ACPY \\
\hline 1 & Mansour and Ali, 2017 & 67 & 13.4 \\
2 & Jin et al., 2019 & 31 & 10.33 \\
3 & Kaya et al., 2020 & 10 & 5 \\
\hline
\end{tabular}

$\mathrm{TC}=$ total citations; ACPY $=$ average citation per year.
Scientia Horticulturae, Plant Disease, and Phytopathology. Top five countries and regions were the United States, PR China, Spain, Brazil, and Japan. The top six organizations were USDA ARS, ARO, Texas A\&M University, Universitat Politecnica de Valencia, University of California-Davis, and Consejo Superior de Investigaciones Cientificas. The top five authors are Gene E. Lester, James D. McCreight, Jordi Garcia-Mas, Kevin M. Crosby, and T.J. Ng. All keywords of the muskmelon research were separated into eight clusters for different research topic. This work is useful for students identifying graduate schools and researchers selecting journals.

\section{Literature Cited}

Belmonte-Ureña, L.J., J.A. Garrido-Cardenas, and F. Camacho-Ferre. 2020. Analysis of world research on grafting in horticultural plants. HortScience 55(1):112-120, doi: https://doi. org/10.21273/HORTSCI14533-19.

Choudhary, D.K. and B.N. Johri. 2009. Interactions of Bacillus spp. and plants- With special reference to induced systemic resistance (ISR). Microbiol. Res. 164(5):493-513, doi: https:// doi.org/10.1016/j.micres.2008.08.007.

Cole, L.J. 1924. A seedless muskmelon. J. Hered. 15:219, doi: https://doi.org/10.1093/oxford journals.jhered.a102452.

Dalla Via, J. and S. Baric. 2012. Tree fruit growing-research and production in Germany: A statistical and bibliometric analysis of the period 1950-2010. Erwerbs-Obstbau 54(1):11-30, doi: https://doi.org/10.1007/s10341-011-0155-2.

Elango, B. and Y.S. Ho. 2017. A bibliometric analysis of highly cited papers from India in Science Citation Index Expanded. Curr. Sci. 112(8): 1653-1658, doi: https://doi.org/10.18520/cs/ v112/i08/1653-1658

Elango, B. and Y.S. Ho. 2018. Top-cited articles in the field of tribology: A bibliometric analysis. COLLNET J. Scientometr. Inf. Manage. 12(2):289-307, doi: https://doi.org/10.1080/ 09737766.2018.1529125.

Farcuh, M., B. Copes, G. Le-Navenec, J. Marroquin, D. Cantu, K.J. Bradford, J.X. Guinard, and A. Van Deynze. 2020. Sensory, physicochemical and volatile compound analysis of short and long shelf-life melon (Cucumis melo L.) genotypes at harvest and after postharvest storage. Food Chem. X 8:100107, doi: https://doi.org/10.1016/ j.fochx.2020.100107.

Garcia-Mas, J., A. Benjak, W. Sanseverino, M Bourgeois, G. Mir, V.M. Gonzalez, E. Henaff, F. Camara, L. Cozzuto, E. Lowy, T. Alioto, S. Capella-Gutierrez, J. Blanca, J. Canizares, P. Ziarsolo, D. Gonzalez-Ibeas, L. RodriguezMoreno, M. Droege, L. Du, M. Alvarez-Tejado, B. Lorente-Galdos, M. Mele, L.M. Yang, Y.Q. Weng, A. Navarro, T. Marques-Bonet, M.A. Aranda, F. Nuez, B. Pico, T. Gabaldon, G. Roma, R. Guigo, J.M. Casacuberta, P. Arus, and P. Puigdomenech. 2012. The genome of melon (Cucumis melo L.). Proc. Natl. Acad. Sci. USA 109(29):11872-11877, doi: https:// doi.org/10.1073/pnas.1205415109.

This study analyzed 2955 papers of global research on muskmelon (Cucumis melo L.) based on WoS from 1924 to 2021. Papers were mainly written in English, by 7883 authors, from 83 countries or territories, from 1697 organizations, and were published in 585 journals and book series. The top five journals were HortScience, Journal of the American Society for Horticultural Science,
Glanzel, W. and R. Veugelers. 2006. Science for wine: A bibliometric assessment of wine and grape research for wine-producing and consuming countries. Amer. J. Enol. Viticult. 57(1): 23-32.

Hirsch, J.E. 2005. An index to quantify an individual's scientific research output. Proc. Natl. Acad. Sci. USA 102(46):16569-16572, doi: https://doi.org/10.1073/pnas.0507655102. 
Hubbard, N.L., S.C. Huber, and D.M. Pharr. 1989. Sucrose phosphate synthase and acid invertase as determinants of sucrose concentration in developing muskmelon (Cucumis-melo L.) fruits. Plant Physiol. 91(4):1527-1534, doi: https://doi. org/10.1104/pp.91.4.1527.

Jamali, H.R., C.C. Steel, and E. Mohammadi. 2020. Wine research and its relationship with wine production: A scientometric analysis of global trends. Austral. J. Grape Wine Res. 26(2):130-138, doi: https://doi.org/10.1111/ajgw.12422.

Jeffrey, C. 1980. A review of the Cucurbitaceae. Bot. J. Linn. Soc. 81(3):233-247, doi: https:// doi.org/10.1111/j.1095-8339.1980.tb01676.x.

Jin, X.Q., T. Liu, J.J. Xu, Z.X. Gao, and X.H. Hu. 2019. Exogenous GABA enhances muskmelon tolerance to salinity-alkalinity stress by regulating redox balance and chlorophyll biosynthesis. BMC Plant Biol. 19:48, doi: https://doi.org/ 10.1186/s12870-019-1660-y.

Kaya, C., M. Ashraf, M.N. Alyemeni, and P. Ahmad. 2020. The role of endogenous nitric oxide in salicylic acid-induced up-regulation of ascorbate-glutathione cycle involved in salinity tolerance of pepper (Capsicum annuum L.) plants. Plant Physiol. Biochem. 147:10-20, doi: https://doi.org/10.1016/j.plaphy.2019.11.040

Khan, A., D. Khan, and F. Akbar. 2020. Bibliometric analysis of publications on research into cotton leaf curl disease. Discoveries (Craiova) 8(2):E109, doi: https://doi.org/10.15190/d.20 20.6 .

Kirkbride, J.H.J. 1993. Biosystematic monograph of the genus Cucumis (Cucurbitaceae): Botanical identification of cucumbers and melons. Parkway Publishers, Boone, NC

Kishor, D.S., Y. Noh, W.H. Song, G.P. Lee, Y Park, J.K. Jung, E.J. Shim, S.C. Sim, and S.M. Chung. 2021. SNP marker assay and candidate gene identification for sex expression viagenotyping-by-sequencing-based genome-wide associations (GWAS) analyses in Oriental melon (Cucumis melo L.var. makuwa). Scientia Hort. 276:109711, doi: https://doi.org/10.1016/j. scienta.2020.109711.

Kloepper, J.W., C.M. Ryu, and S.A. Zhang. 2004. Induced systemic resistance and promotion of plant growth by Bacillus spp. Phytopathology 94(11):1259-1266, doi: https://doi.org/10.1094/ PHYTO.2004.94.11.1259.

Kolle, S.R., T.H. Shankarappa, and Y.S. Ho. 2017. Highly cited articles in science citation index expanded - subject category of horticulture: A bibliometric analysis. Erwerbs-Obstbau 59(2): 133-145, doi: https://doi.org/10.1007/s10341016-0308-4.

Kolle, S.R., T.H. Shankarappa, and T.B.M. Reddy. 2018. Trends in Mango research as seen through Science Citation Expanded Index of Web of Science. Erwerbs-Obstbau 60(3):261270, doi: https://doi.org/10.1007/s10341-0180367-9.

Kulak, M., A. Ozkan, and B. Recep. 2019. A bibliometric analysis of the essential oil-bearing plants exposed to the water stress: How long way we have come and how much further? Scientia Hort. 246:418-436, doi: https://doi. org/10.1016/j.scienta.2018.11.031.

Leiser, H., P. Aventurier, D. Fournier, F. Dosba, and B. Jeannequin. 2009. Tools for producing indicators from a bibliometric study of scientific production: The case of fruit and vegetable publications by the French National Institute for
Agricultural Research (INRA). Fruits 64(5):305312, doi: https://doi.org/10.1051/fruits/2009025.

Lelievre, J.M., A. Latche, B. Jones, M. Bouzayen, and J.C. Pech. 1997. Ethylene and fruit ripening. Physiol. Plant. 101(4):727-739, doi: https:// doi.org/10.1111/j.1399-3054.1997.tb01057.x.

Mansour, M.M.F. and E.F. Ali. 2017. Evaluation of proline functions in saline conditions. Phytochemistry 140:52-68, doi: https://doi.org/ 10.1016/j.phytochem.2017.04.016.

McDonald, M.B. 1999. Seed deterioration: Physiology, repair and assessment. Seed Sci. Technol. 27(1):177-237.

Meira, D., L.G. Woyann, A.H. Bozi, A.S. Milioli, E. Beche, M.C. Panho, L.A. Madella, F. Barrionuevo, V.S. Marchioro, and G. Benin. 2020. Asian soybean rust: A scientometric approach of Phakopsora pachyrhizi studies. Euphytica 216(8):133, doi: https://doi.org/ 10.1007/s10681-020-02667-x.

Miron, D. and A.A. Schaffer. 1991. Sucrose phosphate synthase, sucrose synthase, and invertase activities in developing fruit of lycopersiconesculentum mill and the sucrose accumulating lycopersicon-hirsutum humb and bonpl. Plant Physiol. 95(2):623-627, doi: https://doi.org/ 10.1104/pp.95.2.623.

Raparelli, E. and D. Lolletti. 2020. Research, innovation and development on Corylus avellana through the bibliometric approach. Int. J. Fruit Sci. 20(Suppl. 3):S1280-S1296, doi: https:// doi.org/10.1080/15538362.2020.1784076.

Reyes-Gonzalez, L., C.N. Gonzalez-Brambila, and F. Veloso. 2016. Using coauthorship and citation analysis to identify research groups: A new way to assess performance. Scientometrics 108(3):1171-1191, doi: https://doi.org/10.1007/ s11192-016-2029-8.

Stopar, K., M. Mackiewicz-Talarczyk, and T. Bartol. 2021. Cotton fiber in Web of Science and Scopus: Mapping and visualization of research topics and publishing patterns. J. Nat. Fibers 18(4):547-558, doi: https://doi.org/10.1080/ 15440478.2019 .1636742 .

Sun, J. and B.-Z. Yuan. 2021. Trend and research status of Agronomy based on the Essential Science Indicators during 2009-2019. Agron. J. 113(2):2184-2194. doi: https://doi.org/10.1002/ agj2.20628.

Sun, J. and B.-Z. Yuan. 2019. Visualization analysis of research on rice with fertilizer from the 'Agronomy' category based on CiteSpace. Curr. Sci. 117(9):1449-1458, doi: https://doi. org/10.18520/cs/v117/i9/1449-1458.

Sun, J. and B.-Z. Yuan. 2020a. Mapping of the world rice research: A bibliometric analysis of top papers during 2008-2018. Ann. Library Inf. Studies 67(1):56-66.

Sun, J. and B.-Z. Yuan. 2020b. Bibliometric mapping of top papers in Library and Information Science based on the Essential Science Indicators Database. Malays. J. Libr. Inf. Sci. 25(2):61-76, doi: https://doi.org/10.22452/mjlis.vol25no2.4.

Sun, J. and B.-Z. Yuan. 2020c. Mapping of top papers in the subject category of Water Resources based on the Essential Science Indicators. Ann. Library Inf. Studies 67(2):90-102.

Tang, M., H.C. Liao, Z.J. Wan, E. HerreraViedma, and M.A. Rosen. 2018. Ten years of sustainability (2009 to 2018): A bibliometric overview. Sustainability 10(5):1655, doi: https://doi.org/10.3390/su10051655.
Tatry, M.V., D. Fournier, B. Jeannequin, and F. Dosba. 2011. Tools for analyzing and mapping scholarly publications not indexed by the Web of Science: The case of fruit and vegetable publications by the French National Institute for Agricultural Research (INRA). Fruits 66(2):131-140, doi: https://doi.org/10.1051/fruits/2011022.

Thakur, H., S. Sharma, and M. Thakur. 2019 Recent trends in muskmelon (Cucumis melo L.) research: An overview. J. Hort. Sci. Biotechnol. 94(4):533-547, doi: https://doi.org/ 10.1080/14620316.2018.1561214.

Turgeon, R. and S. Wolf. 2009. Phloem transport: Cellular pathways and molecular trafficking. Annu. Rev. Plant Biol. 60:207-221, doi: https:// doi.org/10.1146/annurev.arplant.043008.092045.

Van Eck, N.J. and L. Waltman. 2010. Software survey: VOSviewer, a computer program for bibliometric mapping. Scientometrics 84(2):523-538, doi: https://doi.org/10.1007/s11192-009-0146-3.

Velasco-Muñoz, J.F., J.A. Aznar-Sánchez, L.J. Belmonte-Ureña, and M.J. López-Serrano. 2018a Advances in water use efficiency in agriculture: A bibliometric analysis. Water 10(4):377, doi: https://doi.org/10.3390/w10040377.

Velasco-Muñoz, J.F., J.A. Aznar-Sánchez, L.J. Belmonte-Ureña, and I.M. Román-Sánchez. 2018b. Sustainable water use in agriculture: A review of worldwide research. Sustainability 10(4):1084, doi: https://doi.org/10.3390/su100 41084.

Wambu, E.W. and Y.S. Ho. 2016. A bibliometric analysis of drinking water research in Africa Water SA. 42(4):612-620, doi: https://doi.org/ 10.4314/wsa.v42i4.12.

Wang, Y.P., W.Z. Liu, G. Li, W.M. Yan, and G.Y. Gao. 2019. A bibliometric analysis of soil and water conservation in the loess tablelandgully region of China. Water 11:20, doi: https://doi.org/10.3390/w11010020.

White-Gibson, A., B. O'Neill, D. Cooper, M. Leonard, and B. O'Daly. 2019. Levels of evidence in pelvic trauma: A bibliometric analysis of the top 50 cited papers. Ir. J. Med. Sci. 188(1):155-159, doi: https://doi.org/10.1007/ s11845-018-1818-x.

Yeung, A.W.K., N.T. Tzvetkov, G. Zengin, D.D. Wang, S.W. Xu, G. Mitrovic, M. Brncic, S Dall'Acqua, V. Pirgozliev, A. Kijjoa, M.I. Georgiev, and A.G. Atanasov. 2019. The berries on the top. J. Berry Res. 9(1):125-139, doi: https://doi.org/10.3233/JBR-180357.

Yuan, B.-Z. and J. Sun. 2019. Bibliometric and mapping of top papers in the subject category of green and sustainable science and technology based on ESI. COLLNET J. Scientometr. Inf. Manage. 13(2):269-289, doi: https://doi. org/10.1080/09737766.2020.1716643.

Yuan, B.-Z. and J. Sun. 2020a. Bibliometric analysis of research on the maize based on top papers during 2009-2019. COLLNET J. Scientometr. Inf. Manage. 14(1):75-92, doi: https:// doi.org/10.1080/09737766.2020.1787110.

Yuan, B.-Z. and J. Sun. 2020b. Mapping the scientific research on maize or corn: A bibliometric analysis of top papers during 2008-2018. Maydica 65(2):M17.

Zhang, J., J.J. Wang, P.C. Wang, and T.T. Guo. 2020. Effect of no-tillage and tillage systems on melon (Cucumis melo L.) yield, nutrient uptake and microbial community structures in greenhouse soils. Folia Hort. 32(2):265-278, doi: https://doi.org/10.2478/fhort-2020-0024. 